\title{
Gregor Kirchhof
}

\section{Die Allgemeinheit des Gesetzes}

Über einen notwendigen Garanten der Freiheit, der Gleichheit und der Demokratie

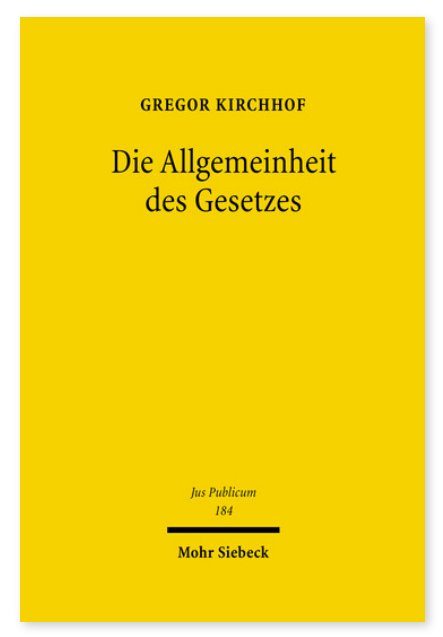

2009. XXI, 715 Seiten. JusPubl 184

ISBN 978-3-16-151265-0

DOI 10.1628/978-3-16-151265-0

eBook PDF 159,00€

ISBN 978-3-16-150149-4

Leinen $159,00 €$
Die Idee des Gesetzes ist die der Allgemeinheit. Dieser ideengeschichtliche Befund droht in Vergessenheit zu geraten. Ausdrückliche rechtliche Allgemeinheitsforderungen werden kaum beachtet. Gesetz ist das, was das rechtsetzende Organ als Gesetz erlässt. Dieser formale Gesetzesbegriff beschreibt die Kernkompetenz des Parlaments. Doch läuft er Gefahr, das große Freiheitsversprechen zu vernachlässigen, das von alters her im allgemeinen Gesetz ruht. Gleichheit ist nur vor einem allgemeinen Gesetz möglich. Das allgemeine Gesetz ergänzt den vom Einzelfall bestimmten Grundrechtsschutz. Die Gesetzesallgemeinheit stärkt die Gestaltungskraft der Gesetze und damit die Demokratie. Gregor Kirchhof fragt in einer Zeit, in der anspruchsvolle Rechtsetzungsaufträge zu erfüllen sind, nach der Allgemeinheit des Gesetzes, nach einem notwendigen Garanten der Freiheit, der Gleichheit und der Demokratie.

Gregor Kirchhof ist Inhaber des Lehrstuhls für Öffentliches Recht, Finanzrecht und Steuerrecht sowie Direktor des Instituts für Wirtschafts- und Steuerrecht an der Universität Augsburg.

Jetzt bestellen:

https://mohrsiebeck.com/buch/die-allgemeinheit-des-gesetzes-9783161512650?no_cache=1

order@mohrsiebeck.com

Telefon: +49 (0)7071-923-17

Telefax: +49 (0)7071-51104 